\title{
Quality of sleep and psychological morbidity among paramedical and medical students in Southwest Nigeria
}

\author{
Ogunsemi, O.O. ${ }^{1}$, *Afe, T.O. ${ }^{1}$, Deji-Agboola M.A. ${ }^{2}$, Osalusi, B.S. ${ }^{1}$, Adeleye, O. ${ }^{1}$, Ale, A. ${ }^{1}$, \\ Shorunmu, T. ${ }^{1}$
}

\begin{abstract}
Objective: The objective of this study was to compare the quality of sleep and psychological morbidity between medical students and paramedical students.

Methods: A cross sectional survey of one hundred and eighty-six students of the College of Medicine, Olabisi Onabanjo University, Ogun State, Nigeria, were surveyed using socio-demographic questionnaires, Pittsburgh Sleep Questionnaire and General Health questionnaire.

Results: The mean ages among paramedical students was $20.63 \pm 1.6$ and medical students was $22.80 \pm 2.93$ respectively. Medical Students had a higher percentage of those who had poor sleep quality $(86.7 \%, \geq 5, \mathrm{n}=85)$ than the paramedical students $(38.6 \%, \mathrm{n}=34)$ and higher mean scores on General Health Questionnaire, $\mathrm{M}(\mathrm{SD})=8.75(5.01)$ than the Paramedical group, $\mathrm{M}(\mathrm{SD})=6.53(2.97)$ respectively.

Conclusion: The findings in our study showed that medical students had poorer sleep quality and higher psychological morbidity in comparison to paramedical students, efforts should be made to reduce academic stress and improving sleep quality.
\end{abstract}

Keywords: Sleep, Psychological Morbidity, Medical Students, Paramedical Students, Medical Education

\author{
*Correspondence Author \\ Afe, T.O., \\ http://orcid.org/0000-0003-2757-367 \\ E-mail: afeet23@yahoo.co.uk \\ ${ }^{1}$ Department of Medicine Olabisi Olabanjo University, Ogun State, Nigeria \\ ${ }^{2}$ Department of Medical Microbiology, Olabisi Onabanjo University, Ago-Iwoye, Nigeria
}




\title{
Qualité du sommeil et psychologie morbide chez les étudiants en médecine et dans le secteur du paramédical dans le sud-ouest du Nigéria.
}

\author{
Ogunsemi, O.O. ${ }^{1}$, *Afe, T.O. ${ }^{1}$, Deji-Agboola M.A. ${ }^{2}$, Osalusi, B.S. ${ }^{1}$, Adeleye, $0 .{ }^{1}$, Ale, A. ${ }^{1}$, \\ Shorunmu, T.
}

\section{Résumé}

Objectif: l'objectif de cette étude était de comparer la qualité du sommeil et de psychologie morbide entre les étudiants en médecine et les étudiants en paramédical.

Méthods: une enquête transversale a été réalisée sur cent quatre-vingt-six étudiants de la Faculté de médecine de l'Université Olabisi Obananjo, dans l'Etat d'Ogun au Nigéria. Ils ont été interrogés par le biais de questionnaires socio-démographiques, d'un questionnaire de sommeil de type «Pittsburgh » et d'un questionnaire sur la santé générale.

Résultats: l'âge moyen chez les étudiants en paramédical s'élevait à 20,63 ans (+ou-1,6), quand celui des étudiants en médecine atteignait 22,8 ans ( + ou $-2,93)$. Les étudiants en médecine ont montré une plus forte tendance à avoir une mauvaise qualité de sommeil $(86,7 \%$ d'entre eux, $\geq 5, n=85)$ que ceux étant en paramédical $(38,6 \%, \mathrm{n}=34)$, et ont obtenu des résultats plus élevés en moyenne sur les questionnaires de santé générale $: \mathrm{M}(\mathrm{SD})=8.75(5.01)$ contre $\mathrm{M}(\mathrm{SD})=6,53(2,97)$ pour le groupe paramédical.

Conclusion: les résultats de notre étude ont montré que les étudiants en médecine avaient une plus mauvaise qualité de sommeil et une plus forte psychologie morbide que ceux étudiant en paramédical. Des efforts doivent être entrepris pour réduire le stress lié aux études et améliorer la qualité de sommeil.

Mots-clés: sommeil, psychologie morbide, étudiants en médecine, étudiants en paramédical, éducation en médecine.

\author{
*Correspondence Author \\ Afe, T.O., \\ http://orcid.org/0000-0003-2757-367 \\ E-mail: afeet23@yahoo.co.uk \\ ${ }^{1}$ Department of Medicine Olabisi Olabanjo University, Ogun State, Nigeria \\ ${ }^{2}$ Department of Medical Microbiology, Olabisi Onabanjo University, Ago-Iwoye, Nigeria
}




\section{INTRODUCTION}

Sleep problems are common among college students (1). The academic workload, tight deadlines and social engagements all contribute to irregular sleep patterns. A number of studies have reported various range of sleep difficulties among college students such as, sleep deprivations, frequent, narcolepsy, and other primary sleep disorders (2) These problems fans across the totality of metrics on which sleep is measured in both the quality (in terms of restorative function) and quantity of sleep (duration).

Previous studies among a group of college students in the southern part of US reported a prevalence of $73 \%$ of college students with some form of sleep difficulty (2). In a large multi-college study, 27\% described their sleep quality as poor, $36 \%$ reported obtaining less than 7 hours of sleep per night, and $43 \%$ reported that it takes $>30$ minutes to fall asleep at least once per week. $62 \%$ of participants met cut-off criteria for poor sleep, though rates differed between females (64\%) and males (57\%) (3). In another survey, it was similarly reported that close to $70 \%$ of college students in US colleges had inadequate sleep (4). Similar results have been reported in other parts of the world among university students (5) .In Nigeria, similar results have been reported. In a recent survey, $50.1 \%$ of the undergraduates surveyed reported various forms of sleep difficulties in one Nigerian university (6).

Multiple factors have been postulated for the high prevalence of sleep difficulties among college students. These ranged from deliberate curtailment of sleep due to the demands of academic workload, social factor and environmental factors such as noisy and uncomfortable residence within universities (4). Additionally, the chronological change accompanying adolescent physiology may also have some impact (7). Further, a myth common among college students is that they always can make up for deliberate sleep deprivation at other times (1).

The consequences of sleep difficulties are quite obvious. Sleep difficulties impairs academic performance, learning and social adjustment $(1,2)$. Long term consequences create difficult psychological and mental health disorders such as depression, anxiety and personality disorders.

A frequently studied group among college students are medical students, who are known to have a high degree of academic and clinical workload (8). The nature of their program creates time constraints which may affect their sleep patterns (8). In a review of studies among medical students across different regions of the world, reported prevalence of sleep problems ranged from $1 \%-90 \%$ of medical students (8). The review also reported significant differences in sleep patterns with higher sleep problems among medical compared to those in law and social sciences (6).

In previous research in Nigeria, medical students have typically been studied in relation to sleep problems due to the belief that the rigorous nature of their academic workload may affect their sleep quality. Previous research has shown a high prevalence of sleep problems among these group of students $(9,10)$. However, a major deficit is the lack of comparative survey across similar backgrounds within the medical field.

This study therefore aims to address this deficit and explore differences in sleep pattern across similar disciplines. Our study compared sleep quality among medical students and paramedical students within a southwest university in Nigeria.

\section{MATERIALS AND METHODS}

The cross sectional study was conducted at the College of Medicine, Olabisi Onabanjo University, Sagamu, Ogun State, Nigeria. First year and second year students were excluded. The first year students were excluded because they were not officially part of the faculties, and second year students because they were new to the rigors of academic environment of the Faculty. The Faculty of Basic Medical Sciences consists of the departments of Anatomy, Biochemistry, Physiology, Pharmacology and Pathology. Apart from the medical students (preclinical), the faculty of basic medical sciences harbor paramedical students in the fields of biochemistry, anatomy, physiology, and pharmacology.

\section{Procedure}

In order to reduce the effect of examination stress on sleep pattern and psychological wellbeing, the survey was conducted far outside the examination period. To allow for a sizable representation, the survey was done during the mandatory lectures that cuts across the various departments in the basic medical sciences ; however, for the medical students (which exams are not semester based) each class (preclinical and clinical)that was selected were very away from their examination period. Trained 
volunteers were used to conduct the questionnaire based survey. Brief introduction and purpose of the study were done. Voluntary participation and consent were obtained from the students after taking permission from the lecturer in-charge of the class. The study protocol was approved by the appropriate authority saddled with the responsibility.

\section{Instruments}

Socio-demographic Questionnaire

A socio-demographic questionnaire was purposely designed capturing relevant sociodemographic details. It included sociodemographic variables such as age, sex, religion, marital status, department.

\section{The Pittsburgh Sleep, Quality Index (PSQI)}

The PSQI is a self-rated instrument that has been variously used in the assessment of sleep quality. It is a 24- item questionnaire that generates seven component scores, ranging from subscale scores 0 to 3: sleep quality, sleep latency, sleep duration, habitual sleep efficiency, sleep disturbances, use of sleep medications and daytime dysfunction.. The global score ranges from 0 to 21(11). The seven component scores each ranging from 0 to 3 ( 0 score equals better and 3 is worst) and one global sleep quality score. The global score of 5 or more designates poor sleep quality while score of less than 5 is considered good sleep quality (11). The PSQI has been validated for use in Nigeria (12). The 7 components that make up the scores, were designed to measure some specific area in the assesment of sleep. Component 1 measures subjective sleep quality, Component 2 measures sleep latency, Component 3 measures sleep duration, Component 4 measures habitual sleep efficiency, Component 5, measures sleep disturbances, Component 6 measures use of sleep medication, and Component 7 meeasures daytime dysfunction.

\section{General Health Questionnaire - 12}

General Health Questionnaire (GHQ) was used in the assessment of psychological distress. It is an easy to use 12-item screening tool. The GHQ 12 was scored using the binary scoring system with a cut -off of 3 and above denoting psychological distress. The GHQ has been variously validated in Nigeria (13).

\section{Data analysis}

The data were analyzed using the Statistical Package for Social Sciences version 2010.
Frequencies, means and other descriptive analysis were used to present the sociodemographic information. Bivariate analyses were used to compare sleep quality across groups. Analysis of Variances were used to explore mean differences in sleep quality. Pvalues were put as $\mathrm{p}<0.05$.

\section{RESULTS}

A total of 240 questionnaires was distributed, out of which 195 were returned, but 186 were suitable for analysis, giving a response rate of $77.5 \%$. For the paramedical students, a total of 88 students were recruited, while for the medical students a total of 98 students were recruited, made up of 48 students from the preclinical and 50 from the clinical students.

Socio-demographic Characteristics and Comparisons of demographics across Paramedical and Medical Participants

The ages ranged between 18- 26 among the paramedical students, while among the medical students the ages ranged between 19 and 30 . Majority of the students in both groups were never married, 93.2\% $(n=82)$, among the paramedical students, $95.9 \%(n=94)$ among the medical students respectively. The largest ethnic group were Yoruba's making up 88.6\%, $(n=78)$ among the paramedical group and $94.9 \%(n=93)$ among medical students. Table 1 also shows comparison of demographics involving age, gender, PSQI and GHQ across both para medical and medical Students. There were significant differences in ages, sex, Global PSQI score and sleep quality respectively at $p=0.00$. Mean ages and distribution of the scores on the Pittsburgh Sleep Questionnaire (PSQI) and General Health Questionnaire (GHQ) are as shown in Table 1. As observed, Medical Students had a higher percentage of those who had poor sleep quality $(86.7 \% \geq 5, \mathrm{n}=85)$ compared to those in the paramedical group $(38.6 \%, n=34)$, respectively. They also had higher mean scores on General Health Questionnaire, $\mathrm{M}(\mathrm{SD})=8.75(5.01)$ than the Paramedical group, $\mathrm{M}(\mathrm{SD})=6.53(2.97)$ respectively .

Comparison of psychological morbidity and sleep quality across demographics of paramedical and medical students

As shown in Tables 2 and 3, there were no significant differences across age, sex, marital status and ethnic groups in both groups. 


\section{Sleep components and relationship with GHQ scores}

Table 4 showed correlations between the components of the PSQI with the total GHQ scores among Medical group and Paramedical Group. Significant correlation were observed with Total GHQ scores with sleep quality, sleep latency, sleep disturbances, use of sleep medication, daytime dysfunction. While among paramedical group, sleep quality, use of sleep medication and daytime dysfunction with GHQ scores.

\section{Comparison of demographic across Clinical and preclinical medical Students}

Table 5 showed that the significant differences were only observed across age with clinical student having higher mean age 24.92(3.90) than those in non clinical 22.77(2.92).

\section{DISCUSSION}

Our study compared the pattern of sleep and psychological morbidity among paramedical and medical students. We observed that there was a high rate of poor sleep quality among the various groups. Among paramedical students, $34.6 \%$ of the participants reported poor sleep quality as measured on the Pittsburgh Sleep Questionnaire index compared to almost 84.6\% among medical group. Generally, college students are at risk of having poor sleep habits. The rates are much higher than the rate reported by a similar study in a Midwest and Southwest region of Nigeria among medical students $(9,10)$. In both studies rates ranged from $32.5 \%$ to $36.6 \%$ were reported among medical students $(9,10)$. Differences in our study may be due to the peculiar characteristics within the college environment in which majority of the students live outside the university campus, and the nature of the sample size, i.e both clinical and non clinical students that were included in the study.

A major reason for the poorer quality of sleep among medical students is probably the nature of academic workload, attitudes, knowledge of sleep $(9,10)$. Notably, in comparison to other paramedical students, the rigorous nature of medical studies and not just the volume bears a higher toll on medical students compared to their mates at similar levels in the tertiary system. The demands are much higher, and more strenuous. In order to keep up with the demands expected of them, many strive to sacrifice healthy sleep habits for poor sleeping habits.

Our study replicates similar studies on sleep patterns among tertiary students (5). Our study had higher prevalence of poor quality sleep than what was reported in a similar study among college students ( $25 \%$ of study sample) in US and Saudi Arabia $(3,8)$. Also, results from our study is similar to what was reported in India when medical students were compared to paramedical students (15).

In our Study, there were no significant differences across socio-demographic characteristics in regards to sleep quality. Although females were in majority in both groups, our results mirror similar findings in Nigeria $(9,10)$. Our study showed higher level of psychological morbidity among medical students compared to paramedical students. Previous research in similar setting has reported similar psychological morbidity among medical students and possible areas of stress which included academic workload, length of stay, having no one to talk to (16). In other climes, the level of stress of the academic workload have been a source of sleep difficulties among medical students (17). Comparatively our result suggests that medical students have higher level of psychological morbidity than paramedical students. Further as noted, the sleep quality among medical students strongly correlated with psychological morbidity. This indicates that the high psychological morbidity was related to the poor quality of sleep.

Interestingly, from our findings, we observed five areas that were significantly correlated with psychological morbidity among medical students, these included sleep quality, sleep latency, habitual sleep disturbances, use of sleep medications and daytime dysfunction, in comparison to three areas among paramedical group, which were sleep quality, use of sleep medication, daytime dysfunction.

Our study also pioneered differences across non-clinical and clinical student within our region. The findings showed that there were not significant differences across sociodemographic characteristics, in relation to their quality of sleep and psychological morbidity. The observations probably highlights a characteristic peculiarity that spans the length of medical training. Obviously, the need to reassess the curriculum and revisit the nature of the ever increasing work-load, length of stay and counseling programs is necessary in order to help reduce sleep problem and psychological morbidity among medical and paramedical students. 


\section{CONCLUSION}

The study showed that medical student have poor sleep and higher psychological morbidity than the paramedical students. It is imperative that tutors need to engage students on the need for adequate rest and avoid frequent late-nights deadlines, sleep educational programs, encouragement of naps (4).

Limitation: A major limitation of our study is the localization to the study setting and the noninclusion of other students from different institutions.

Acknowledgments: We wish to acknowledge the students of Olabisi Onabanjo University, Ogun State, Nigeria.

Conflict of interest: The authors declare no conflicts of interest.

\section{REFERENCES}

1. Gaultner, JF The prevalence of sleep disorders in college students: impact on academic performance, Journal of American College Health, 2010: 59: (2), 91-97.

2. Buboltz Jr WC, Brown F, Soper B. Sleep habits and patterns of college students: a preliminary study. Journal of American College Health, 2001: 50:1, 131- 135.

3. Becker, S. P., Jarrett, M. A., Luebbe, A. M., Garner, A. A., Burns, G. L., \& Kofler, M. J.). Sleep in a large, multi-university sample of college students: sleep problem prevalence, sex differences, and mental health correlates. Sleep health, 2018.4(2), 174-181.

4. Hershner SD, Cherwin RD . Causes and consequences of sleepiness among college students. Nature and Science of Sleep, 2014; 6: 73-84.

5. Amaral, A. P., Soares, M. J., Pinto, A. M., Pereira, A. T., Madeira, N., Bos, S. C., ... \& Macedo, A. (2018). Sleep difficulties in college students: The role of stress, affect and cognitive processes. Psychiatry research, 260, 331-337

6. Seun-Fadipe CT, Mosaku KS. Sleep quality and psychological distress among undergraduate students of a Nigerian university. Sleep Health: Journal of the National Sleep Foundation. 2017 Jun 1;3(3):190-4.

7. Carskadon MA, Vieira C, Acebo C. Association between puberty and delayed phase
preference.Sleep,1993.; 16(3):258-262

8. Azad MC, Fraser K, Rumana N, Abdullah AF, Shahana N, Hanly PJ, Turin TC (2015). Sleep disturbances among medical students: a global perspective, J Clin Sleep Med, 2015;,:11(1):69-74.

9. James BO, Omoaregba JO, Igberase OO. Prevalence and correlates of poor sleep qualityamong medical students at a Nigerian university. Annals of Nigerian Medicine ,2011; 5(1): 1-5.

10. Abdulghani HM, Alrowais NA, Bin-Saad NS, AlSubaie NM, Haji AM, Alhaqwi AI. Sleep disorder among medical students: relationship to their academic performance. Medical teacher. 2012 Apr 1;34(sup1):S37-41.

11. Uysse DJ, Reynolds CF, Timothy HM, Susan RB, David JK. The Pittsburgh sleep quality index: A new instrument for psychiatric practice and research, Psychiatric Research 1988; 28:193-213

12. Aloba OO, Adewuya AO, Ola BA, Mapayi BM. Validity of the Pittsburgh sleep quality index (PSQI) among Nigerian university students Sleep medicine; 2015; 8(3), 266-70.

13. Gureje O, Lasebikan VO, Kola L, Makanjuola VA. Lifetime and 12-month prevalence of mental disorders in the Nigerian Survey of Mental Health and Well-Being. Br J Psychiatry. 2006 May;188:465-471.

14. IBM Corp. Released 2011. IBM SPSS Statistics for Windows, Version 20.0. Armonk, NY: IBM Corp

15. Chutani A, Shenvi DN, Singhal A. Sleep, Sleepiness and Medical College Students: A Comparative Study among Medical and Paramedical Students of a Tertiary Care Teaching Hospital from a West Indian Metropolitan City. Annals of Medical and Health Sciences Research. 2017;7(2):85-91.

16. Ogunsemi OO, Afe TO, Oguntona AS, Adefuye BO.Psychological wellbeing of medical students. Research Journal of Health Sciences, 2015; 1:9098.

17. Piro, R. S., Alhakem, S. S. M., Azzez, S. S., \& Abdulah, D. M. Prevalence of sleep disorders and their impact on academic performance in medical students/University of Duhok. Sleep and Biological Rhythms, 2018; 1-8. 
Table 1. Socio-demographic Characteristics of participants

\begin{tabular}{|c|c|c|c|c|}
\hline Variables & Paramedical & Medical & test statistics & p \\
\hline Age range (Mean) & $17-26(20.63 \pm 1.6)$ & $19-30(22.80 \pm 2.93)$ & $\mathrm{t}=7.78$ & 0.00 \\
\hline \multicolumn{5}{|l|}{ Gender } \\
\hline Female & $75(85.2 \%)$ & $54(55.1 \%)$ & & \\
\hline Male & $13(14.80 \%)$ & $44(44.9 \%)$ & $x^{2}=14.79$ & 0.00 \\
\hline \multicolumn{5}{|l|}{ Ethnic group } \\
\hline Yorubas & $78(88.6 \%)$ & $93(94.9 \%)$ & & \\
\hline Ibos & $5(5.7 \%)$ & $5(5.1 \%)$ & $\mathrm{F}=0.20$ & 0.00 \\
\hline Others & $5(5.7 \%)$ & 0 & & \\
\hline \multicolumn{5}{|l|}{ Marital Status } \\
\hline Single & $82(93.2 \%)$ & $94(95.9 \%)$ & & \\
\hline Married & $6(6.8 \%)$ & $4(4.1 \%)$ & $x^{2}=0.65$ & 0.48 \\
\hline Separated/widowed/divorced & 0 & 0 & & \\
\hline Global PSQI Score & $4.33(2.83)$ & $7.01(2.64)$ & $t=6.13$ & 0.00 \\
\hline \multicolumn{5}{|l|}{ PSQI } \\
\hline Good sleep quality & $54(61.4 \%)$. & $15(15.4 \%)$ & & \\
\hline Poor sleep quality & $34(38.6 \%)$ & $83(84.6 \%)$ & $X^{2}=34.54$ & 0.00 \\
\hline GHQ mean score & $6.53(2.97)$ & $8.75(5.01)$ & $\mathrm{t}=4.07$ & 000 \\
\hline No Morbidity & $14(15.9 \%)$ & $12(12.2 \%)$ & $X^{2}=0.47$ & 0.52 \\
\hline Positive Morbidity & $74(84.1 \%)$ & $86(87.8 \%)$ & & \\
\hline
\end{tabular}

Table 2. Comparison of Psychological Morbidity across Medical and Paramedical demographics

\begin{tabular}{|c|c|c|c|c|c|c|c|c|}
\hline \multirow[t]{2}{*}{ Demographics } & \multicolumn{2}{|c|}{$\begin{array}{l}\text { Medical } \\
\text { GHQ }\end{array}$} & \multicolumn{6}{|c|}{$\begin{array}{l}\text { Paramedical } \\
\text { GHQ }\end{array}$} \\
\hline & $\leq 2$ & Test & Statistics & $\mathrm{p}$ & $\leq 2$ & $\geq 3$ & test statistics & $\mathrm{p}$ \\
\hline Age & 20.60 & 20.65 & $\mathrm{t}=-0.02$ & 0.98 & 23.75 & 24.60 & $\mathrm{t}=-0.78$ & 0.44 \\
\hline \multicolumn{9}{|l|}{ Sex } \\
\hline Male & $2(4.5 \%)$ & $42(95.5 \%)$ & $\mathrm{X}^{2}=0.8$ & 0.80 & $3(15.4 \%)$ & $9(84.6 \%)$ & & \\
\hline Female & $3(5.6 \%)$ & $51(94.4 \%)$ & & & $11(14.5 \%)$ & $65(85.5 \%)$ & $\mathrm{X}^{2}=0.93$ & 0.34 \\
\hline \multicolumn{9}{|l|}{ Marital Status } \\
\hline \multicolumn{9}{|l|}{ Single } \\
\hline \multirow[t]{2}{*}{ Married } & $5(5.3 \%)$ & $89(94.7 \%)$ & $X^{2}=0.24$ & 0.62 & $6(7.3 \%)$ & $76(92.7 \%)$ & & \\
\hline & & $4(100 \%)$ & & & $1(20.0 \%)$ & $5(80.0 \%)$ & $X^{2}=054$ & 0.46 \\
\hline \multicolumn{9}{|l|}{ Ethnic group } \\
\hline Yorubas & $5(5.4 \%$ & o) $88(94.6 \%)$ & $\mathrm{X}^{2}=0.24$ & 0.63 & $6(7.7 \%)$ & $72(92.3 \%)$ & & \\
\hline Ibos & 0 & $4(100 \%)$ & & & 0 & $5(100 \%)$ & & \\
\hline Others & & & & & 0 & $5(100 \%)$ & ${ }^{2} \neq 0.93$ & 0.62 \\
\hline
\end{tabular}


Table 3 : Comparison of Sleep Quality among Medical and Paramedical demographics

\begin{tabular}{|c|c|c|c|c|c|c|c|c|}
\hline Demographics & $\begin{array}{l}\text { Medical } \\
\text { PSQ } \\
<5\end{array}$ & $\geq 5$ & Test & $p$ & $\begin{array}{l}\text { Paramedical } \\
\text { PSQ } \\
<5 \quad \geq 5\end{array}$ & & test & $p$ \\
\hline Age & 21.02 & 20.31 & $\mathrm{t}=1.64$ & 0.11 & 23.53 & 26.40 & $\mathrm{t}=-2.78$ & $0.00 *$ \\
\hline $\begin{array}{l}\text { Sex } \\
\text { Male } \\
\text { Female }\end{array}$ & $\begin{array}{l}3(6.8 \%) \\
12(22.2 \%)\end{array}$ & $\begin{array}{l}41(93.2 \%) \\
42(77.3 \%)\end{array}$ & $x^{2=} 1.90$ & 0.22 & $\begin{array}{l}6(46.2 \%) \\
48(64.0 \%)\end{array}$ & $\begin{array}{l}7(53.8 \%) \\
27(36.0 \%)\end{array}$ & $x^{2=} 1.37$ & 0.24 \\
\hline $\begin{array}{l}\text { Marital Status } \\
\text { Single } \\
\text { Married }\end{array}$ & $\begin{array}{l}14(14.9 \%) \\
1(25.0 \%)\end{array}$ & $\begin{array}{l}80(85.1 \%) \\
3(75.0 \%)\end{array}$ & $x^{2}=0.25$ & 0.52 & $\begin{array}{l}53(65.0 \%) \\
1(20.0 \%)\end{array}$ & $\begin{array}{l}29(35.0 \%) \\
5(80.0 \%)\end{array}$ & $\mathrm{x}^{2=} 1.31$ & 0.24 \\
\hline $\begin{array}{l}\text { Ethnic group } \\
\text { Yorubas } \\
\text { Ibos } \\
\text { Others }\end{array}$ & $\begin{array}{l}15(16.0 \%) \\
0\end{array}$ & $\begin{array}{l}78(84.0 \%) \\
5(100 \%)\end{array}$ & $x^{2}=0.79$ & 0.37 & $\begin{array}{l}47(60.0 \%) \\
4(80.0 \%) \\
3(75.0 \%)\end{array}$ & $\begin{array}{l}31(40.0 \%) \\
1(100 \%) \\
1(25.0 \%)\end{array}$ & $x^{2}=0.93$ & 0.62 \\
\hline
\end{tabular}

Table 4. Correlations between components of PSQI and Total GHQ scores

\begin{tabular}{rlll}
\hline Variables & $\begin{array}{l}\text { Paramedical } \\
\text { Total GHQ }(\mathrm{r})\end{array}$ & $\begin{array}{l}\text { Medical } \\
\text { Total GHQ }\end{array}$ \\
\hline 1. & Subjective Sleep Quality & $0.27^{*}(\mathrm{p}=0.00)$ & $0.55^{*}(\mathrm{p}=0.00)$ \\
2. & Sleep Latency & 0.07 & $0.43^{*}(\mathrm{p}=0.00)$ \\
3. & Sleep duration & -0.02 & 0.09 \\
4. & Habitual Sleep Efficiency & 0.05 & 0.11 \\
5. Sleep disturbances & 0.13 & $0.35^{*}(\mathrm{p}=0.00)$ \\
6. Use of Sleeping Medication & $0.27^{*}(\mathrm{p}=0.00)$ & $0.39^{*}(\mathrm{p}=0.00)$ \\
7. & Daytime Dysfunction & $0.30^{*}(\mathrm{p}=0.00)$ & $0.53^{*}(\mathrm{p}=0.00)$ \\
8. & Total PSQI scores & $0.53^{*}(\mathrm{p}=0.00)$ & 0.23 \\
\hline
\end{tabular}


Table 5: Comparison of demographics across Clinical and Preclinical medical students

\begin{tabular}{llll}
\hline Variables & \multicolumn{1}{c}{ Clinical } & \multicolumn{1}{c}{ Preclinical } & Test statistics \\
\hline Age & $24.92(3.90)$ & $22.77(2.92)$ & $\mathrm{t}=2.95 \quad \mathrm{p}=0.00$ \\
Sex & & & \\
Male & $22(45.8 \%)$ & $22(44.0 \%)$ & \\
Female & $26(54.2 \%)$ & $28(56.0 \%)$ & $\mathrm{x}^{2}=0.33, \mathrm{p}=0.86$ \\
Marital Status & & & \\
Single & $45(93.7 \%)$ & $49(98.0 \%)$ & \\
Married & $3(6.3 \%)$ & $1(2.0 \%)$ & $\mathrm{x}^{2}=1.09, \mathrm{x}^{2}=0.30$ \\
Ethnic Group & & & \\
Yoruba & $46(95.8 \%)$ & $47(94.0 \%)$ & \\
Others & $2(4,2 \%)$ & $3(6.0 \%)$ & $\mathrm{x}^{2}=0.17,0.68$ \\
GHQ & & & \\
GHQ $\leq 2$ & $4(8.3 \%)$ & $1(2.0 \%)$ & \\
GHQ $\geq 3$ & $44(91.7 \%)$ & $49(98.0 \%)$ & $\mathrm{X}^{2}=1.97,0.16$ \\
PSQ & & & \\
PSQ $<5$ & $9(18.7 \%)$ & $6(12.0 \%)$ & \\
PSQ $\leq 5$ & $39(81.3 \%)$ & $44(88.0 \%)$ & $\mathrm{X}^{2}=0.90,0.34$ \\
\hline
\end{tabular}

